\title{
Mathematics Performance of the Students in Primary School: Comparison of Working Memory Capacity and Inhibition
}

\author{
Fatemeh Chamandar ${ }^{1}$, Susan Jabbari ${ }^{2}$, Maryam Poorghorban ${ }^{3}$, Maryam Shafiei Sarvestani ${ }^{4} \&$ Sahar Amini $^{5}$ \\ ${ }^{1}$ Special Education Department, College of Education, Shiraz University, Shiraz, Iran \\ ${ }^{2}$ Curriculum Development, College of Education, Shiraz University, Shiraz, Iran \\ ${ }^{3}$ Educational Psychology, College of Education, Tehran University, Iran \\ ${ }^{4}$ Administration and Educational Planning, College of Education, Shiraz University, Iran \\ ${ }^{5}$ Psychology and Exceptional Children Education, Azad University, Science Research Branch, Tehran, Iran \\ Correspondence: Fatemeh Chamandar, Exceptional Children Psychology, College of Education, Shiraz University, \\ Shiraz, Iran. E-mail: fchamandar@gmail.com
}

Received: February 1, 2019 Accepted: April 28, $2019 \quad$ Online Published: May 27, 2019

doi:10.5539/jel.v8n3p242 URL: https://doi.org/10.5539/jel.v8n3p242

\begin{abstract}
Research has highlighted the role of working memory and inhibition on the performance of pupils in mathematics. This study was an attempt to look into the relationship between executive function including working memory capacity and inhibition on the one hand and mathematical abilities on the other. 30 primary school students were selected from among the 4th graders, forming two groups of students with high achievement in mathematics (strong) and those with low achievement in mathematics (poor) with the closes possible reading ability and IQ. The two groups were compared with regards to working memory, which was measured via Wechsler intelligence test, and inhibition, which was measured using the Stroop test. The data collected for these measures were analyzed using ANOVA. The results of the $\mathrm{T}$ test showed that the poor group performance on inhibition and working memory was significantly lower than strong group. The findings indicate the importance of these actions (inhibition and working memory) on math performance of students.
\end{abstract}

Keywords: executive function, inhibition, working memory, math performance, primary school

\section{Introduction}

The teaching of mathematics is a primary objective of schooling. Problems in learning mathematics generally appears in primary school and can persist to high school (Gersten, Jordan, \& Flojo, 2005).

These problems not only lead to poor school performance, but the failure to learn mathematical skills can impact on a person's life as mathematics teaches logic, decision making, and problem-solving skills. Early diagnosis of problems with math performance is important to ensure children are provided with remedial support. Appropriate support for children requires that attention be paid to individual differences in learning ability and the factors related to acquisition of mathematical skills. Studies have identified three main factors that influence math performance: (1) cognitive, (2) metacognitive (self-regulated learning and self-checking), and (3) motivational (Montague \& Applegate, 1993). These factors are a part of the broader set of executive functions children require for learning at school (Blair, Zelazo, \& Greenberg, 2005; McCloskey, Perkins, \& Van Divner, 2008) and conducting daily activities (Zelazo et al., 2003). The present paper aimed at investigating the relationship between executive functions and mathematics performance.

Inhibition and working memory are generally regarded as the main components of executive functions (Gioia \& Isquith, 2004; Pennington \& Ozonoff, 1996). Working memory is essential for carrying out complex tasks such as reading comprehension (Cain, Oakhill, \& Bryant 2004; Stevenson, Bergwerff, Heisera, \& Resinga, 2014), understanding, reasoning, and learning, and is therefore critical for learning math (Arndt, Sahr, Opfermann et al., 2013). The different components of working memory contribute to math problem solving in different proportions. Researchers have presented contradictory findings in this respect. Some have stressed the key role of the various working memory components, yet some others have underestimated their role (Zheng, Swanson, \& Marcoulides, 2011). Bull and Scerif (2001) measured the abilities of a group of children by math tests and found mathematical 
abilities have a significant relationship with performance of executive functions including inhibition, movement, and working memory. Papadakis, Kalogiannakis and Zaranis (2017) found that the didactic approach, helped children who had weak memory mechanisms to improve their mathematical ability significantly.

They, however, found that this relationship significantly diminishes when reading comprehension and intelligence are statistically controlled. Different findings on the role served by particular components of the working memory in mathematics could be explained as follows: individual differences in reading comprehension ability play a mediating role between the working memory and mathematics, and when the effect of reading comprehension is controlled, there will be a significant decline in the relationship (Swanson, Coone, \& Brock, 1993 cited in Zheng, Swanson, \& Marcoulides, 2011). Therefore, further research is required in the area. Inhibition occurs when a thought or function must be abruptly stopped to help the child ignore the information he/she does not need (Nigg, Blaskey, Huang-Pollock, \& Rappley, 2002). According to this model, 'partial control' of inhibition can risk working memory capabilities and interfere with planning and organization of behavior (Valera \& Seidman, 2006). Inhibition can properly predict counting, but it is not as effective in calculation and mostly predicts mathematical achievements in rather simpler processes (Lan, legare, Ponitz, \& Morrison, 2011; Molfese, Molfese, Molfese, Rudasill, Armstrong, \& Starkey, 2010). However, Blair and Razza (2007) reported that the inhibition skills which they measured in children predict mathematics and basic knowledge. Moreover, they found that inhibition can especially contribute to mathematical knowledge even when intelligence and attention are controlled. Others (e.g., Swanson \& Lee, 2001) believe that inability to stop and inhibit irrelevant information can exert influence on different mathematical abilities including retrieving numerical realities from the long-term memory.

Conducting a study on elementary school students, Visu-Petra, Cheiea, Benga and Miclea (2011) found that working memory extensively influences educational performance, particularly in math classes and math tests. The study also showed that inhibition serves the most important role in explaining the variation in scores in a class; however, this role is not as important in math performance. Yet, other researchers hold that there is no difference in working memory size (forward and backward memory span and corsi block) in students with math problems and those without (Temple \& Sherwood, 2002; Butterworth, 2005). In the light of contradictory results on the relative importance of different executive functions and math performance, the present study investigated the role played by the working memory and inhibition in math performance in a group of grade 4 students, while controlling for intelligence and reading comprehension.

\section{Method}

\subsection{Participants}

The study entailed 30 children aging 10 and studying in grade 4 (Mean $=10.33, \mathrm{SD}=2.85)$ of elementary schools from the different suburbs of Yazd (6th biggest city in Iran, population: $1.07 \mathrm{~m}$ ). A casual-comparative study, the present attempt was carried out to evaluate math performance (dependent variable) with respect to executive functions (independent variable).

Teachers were requested to provide the researcher with a list of students who were high achievers in mathematics (25 participants).

A math test was administered to ensure that these students could be regarded as 'high achievement'; students not found to be 'high-achieving' in mathematics were excluded from the study. Also, the teachers were requested to provide the researcher with a list of low-achieving students in their math classes (25 participants). Similarly, a math test was carried out to ensure that these participants had in fact low achievements. Students not found to be 'low-achieving' in mathematics were eliminated from the study. Students in both the low-achieving group and high-achieving groups were administered the intelligence and reading comprehension test. Students whose scores on the intelligence was below 85 or above 115, and whose scores on the reading comprehension tests were in the bottom $30 \%$ or the top $70 \%$ were excluded from the study. Students with a high discrepancy between age and grade were also eliminated from the study.

Students were split into 'low-achieving' and 'high-achieving' groups as described below:

(a) The low-achieving group, encompassing 15 students with average reading comprehension ability (30-70\%) and an IQ score of below 90. (b) The high-achieving group, including 15 students with average reading comprehension ability (30-70\%) and an IQ score of above 110. Students in both groups were administered the test of executive functioning.

\subsection{Procedure}

All the tests were administered in a quiet school room. The tests were taken individually. Testing sessions lasted around 1 hour, including a ( $\mathrm{x}$ minute break time). The order of the tests to be taken was changed for each 
participant so as to avoid interference of the test sequence.

\subsection{Measures}

\subsubsection{Iran Key-Math Test}

This test, devised by Connolly in 1988, is widely administered to identify students who have math disabilities (Connolly, 1988). The contents of the test entails areas of Basic Concepts, Operations, and Applications. The predictive, discriminant, content, and concurrent validities were measured besides the test difficulty and correlation of each item with each subtest as well as the whole test. The test validity is presented in Cronbach's alpha, ranging from 0.80 to 0.84 in 5 grades. The raw score pertaining to the whole test, i.e., the sum total of all the subtests, is presented in a standard average score of 100 with a standard deviation of 15 . The standard scores are generally displayed based on either class (class(es) across the province or country whose raw scores have been utilized to standardize the score) or age (average performance at a certain age). This study used the latter.

\subsubsection{Reading Comprehension}

The reading comprehension test devised by Karami, Nouri and Moradi (2008) was adopted for the present study. It measures reading comprehension ability in normal primary school students. Assessment of the score of each subtest is carried out based on the sum of the right answers. The subtests of the test encompass reading non-words, words, and chains of words. Measurement of both the student's reading level and progress hinges upon adoption of a reliable test. One of the easiest and most comprehensive tests in this regard is the word list.

The test score is normalized for both monolingual Persian students and bilingual students in Sanandaj in Kordestan province and Tabriz in East Azarbayejan Province, Iran. According to the developers, the test's Cronbach's alpha is 0.82 .

\subsubsection{Wechsler Intelligence Scale for Children}

Wechsler Intelligence Scale for Children was devised by Wechsler in 1949 and revised in 1974. The test became known as Wechsler Intelligence Scale for Children (wisc-r) after it was normalized. It was normalized for Iran by Shahim (1995) with a test-retest reliability of 0.44-0.94. This study benefited picture completion and binary form as they can evaluate both verbal and non-verbal skills. In addition, they are more advantageous than other binary forms which strongly correlate with IQ score e.g., cubes or words. Therefore, these tests are preferred over other binary forms since they benefit parallel forms. The reliability of these tests is 0.87 .

\subsubsection{Memory Span Test}

Forward and backward digit memory span tests, which are the revised Persian versions of Wechsler Intelligence Scale for Children (Shahim, 1994), were used to measure working memory span. In forward digit memory span test, one digit will be added at each stage with the first stage including a 3-digit number and the last including a 9-digit number in each column. Participants are required to repeat the numbers they hear. In the backward digit memory span test, one digit is added at each stage in each column. The first stage includes a 2-digit number and the last includes an 8-digit number.

Participants are required to repeat the number they hear in a backward order.

Since there are two columns in each task, there are two scores. If one column is repeated correctly, the participant will score 1, and if there is failure in repetition of both columns, the test is stopped. A high score in forward and backward digit memory span tests represents a high working memory capacity. Clair-Thompson and Gathercole (2006) obtained the reliability of the backward digit memory span test to be 0.71 and Alloway (2006) obtained the test-retest reliability of the forward and backward digit memory span tests to be 0.84 and 0.6 , accordingly.

\subsubsection{Stroop Test}

One of the methods used for measuring the executive function is Stroop Interference Test. Developed by Stroop in 1935, this test is used for measurement of cognitive flexibility and selective attention. It is generally regarded as the measurement of the ability to shift cognitive set (Spreen \& Strauss, 1998) and cognitive inhibition (Archibald \& Kerns, 1999; Boone, Miller, Lesser, Hill, \& D'Elia, 1990) or the ability to inhibit an overlearned, i.e., a dominant, response rather than an unusual response (Spreen \& Strauss, 1998). This test is a rapid measure frequently adopted for screening brain damage.

The present study used the Victoria version of this test (Spreen \& Strauss, 1998). In the first stage, i.e., the baseline stage, the child is asked to quickly read the words 'green', 'yellow', 'blue', and 'red', which are all printed in black. The second stage involves the congruent condition, in which the child is asked to read the word 'blue' which is, for instance, printed in green. In the third stage, which is called the incongruent condition, the participant is required to 
name the color used for printing the words instead of reading the word printed (the response in this case is 'green'). In each stage, there are 24 words arranged randomly. The time span and the number of errors are recorded. Three scores have been used in this study for measuring the inhibition: (1) Interference score, which results from the interference of the time for performing the incongruent condition and the time for performing the baseline stage. A high positive score indicates the great role played by the interfering elements in the incongruent condition. (2) Facilitation score, which results from subtracting the time for the congruent condition and the time for the baseline stage. A high positive score indicates the great role which the facilitating elements serve in the congruent condition. (3) The number of the errors in the 3rd stage, which demonstrates the inability in dominant response inhibition (Wolf, 2004). The test-retest reliability of this test has been reported between 0.80 and 0.91 (Baron, 2004; Gorfein \& MacLeod, 2007; Hannay Loring, Howieson, \& Lezak, 2004).

\subsection{Data Analysis}

SPSS v21 (IBM Corp, 2012) was used for the statistical analyses. Comparison of the groups was carried out using ANOVA. One sample t-test was utilized just for the weaker group. Covariance was used to statistically control intelligence and reading comprehension.

\section{Results}

Table 1 presents the results of the Univariate Analysis of Variance for the two homogeneous groups with respect to the dependent variables.

Table 1. The results of the Univariate Analysis of Variance

\begin{tabular}{|c|c|c|c|c|c|c|c|c|}
\hline \multirow[t]{2}{*}{ Items } & \multicolumn{2}{|c|}{ Weak group $n=15$} & \multicolumn{2}{|c|}{ Strong group $n=15$} & \multicolumn{4}{|c|}{ One sample t-test } \\
\hline & Mean & SD & Mean & $\mathrm{SD}$ & & $\eta$ & $\mathrm{P}$ & $F$ \\
\hline \multirow[t]{2}{*}{ Working memory } & $7 / 93$ & $1 / 66$ & $12 / 73$ & $1 / 28$ & Uncontrolled & $0 / 73$ & $0 / 001$ & $78 / 20$ \\
\hline & & & & & Controlled & $0 / 59$ & $0 / 001$ & $35 / 3$ \\
\hline \multirow[t]{2}{*}{ Facilitation score } & $2 / 33$ & $1 / 83$ & $1 / 33$ & $1 / 34$ & Uncontrolled & $0 / 09$ & $0 / 10$ & $2 / 89$ \\
\hline & & & & & Controlled & $0 / 04$ & $0 / 29$ & $1 / 12$ \\
\hline \multirow[t]{2}{*}{ Interference score } & $33 / .$. & $13 / 10$ & $27 / 13$ & $9 / 10$ & Uncontrolled & $0 / 06$ & $0 / 16$ & $2 / 02$ \\
\hline & & & & & Controlled & $0 / 07$ & $0 / 18$ & $1 / 88$ \\
\hline
\end{tabular}

\subsection{Working Memory}

Analysis of Variance was used to test the difference between the two groups in the working memory performance so that these results could be compared to the results obtained from the covariance analysis. The Levene test indicated that the variances were homogeneous $(\mathrm{p}=0.31, \mathrm{~F}(1.28)=1.06)$. A comparison of the students in the strong and weak groups with no control over the working memory indicated that the working memory was significantly higher in the strong group $(\mathrm{M}=12.73)$ than the weak group $(\mathrm{M}=7.93)(\mathrm{p}=0.00, \mathrm{~F}(1.28)=78.20)$. To indicate whether this difference was caused by the non-executive functions of the working memory, a covariance analysis was performed while IQ was controlled. The results showed that even after controlling the IQ, the performance of the low-achieving group was significantly lower than the high-achieving group $(p=0.00, F(1.27)$ $=35.34$ ). When the reading comprehension score (words, chains of words, and non-words) was controlled in addition to the IQ, the performance of the high-achieving group was still significantly higher than the low-achieving group $(\mathrm{p}=0.00, \mathrm{~F}(1.24)=35.29)$.

\subsection{Inhibition}

The Univariate Analysis of Variance served to find the differences between the groups for response inhibition so that a comparison could be made between this analysis and the covariance analysis presented in Table 1 . The results of the Levene Test-indicated homogeneous variances $(p=0.14, F(1.28)=2.20)$. The variance analysis demonstrated that when the low-achieving and high-achieving groups were compared without controlling the facilitation, there was no significant difference between the facilitation score of the high-achieving $(\mathrm{M}=1.33)$ and the low-achieving group $(\mathrm{M}=2.33)(\mathrm{p}=0.10, \mathrm{~F}(1.28)=2.89)$. Even while intelligence served as the control variable, the two groups did not show a significant difference $(\mathrm{p}=0.28, \mathrm{~F}(1.27)=1.17)$, and when in addition to intelligence, reading comprehension (words, chains of words, and non-words) was also controlled, still no significant difference could be observed between the two groups $(p=0.29, F(1.24)=1.13)$. Based on the results of the variance analysis while interference was not controlled, no significant difference was observed for the high-achieving group $(\mathrm{M}=27.13)$ and the low-achieving group $(\mathrm{M}=33.00)(\mathrm{p}=0.16, \mathrm{~F}(1.28)=2.02)$ for the interference score. The Levene Test demonstrated homogeneous variances $(p=0.16, F(1.32)=5.67)$. Even when 
intelligence was controlled, the groups did not exhibit a significant difference $(p=0.31, F(1.27)=1.07)$. And when the reading comprehension (words, chains of words, and non-words) was considered as the control variable, still no significant difference was observed between the groups $(\mathrm{p}=0.18, \mathrm{~F}(1.24)=1.88)$

Table 2. Mean and standard deviation of the errors for the low-achieving group

\begin{tabular}{lllll}
\hline Weak group & $\mathrm{M}$ & $\mathrm{SD}$ & $\mathrm{N}$ & Mean standard score \\
\hline Error & $1 / 27$ & $1 / 22$ & 15 & $0 / 32$ \\
\hline
\end{tabular}

Table 3. T-test results

\begin{tabular}{lllllll}
\hline Weak group & T & Df & Sig Mean & difference & \multicolumn{2}{c}{ 95\% confidence interval } \\
\hline Error & $4 / 01$ & 14 & $0 / 00$ & $1 / 27$ & Lowe & upper \\
& & & & & $0 / 59$ & $1 / 94$ \\
\hline
\end{tabular}

Note. $\mathrm{p}<.05$.

Given the results of Tables 2 and 3, the value for $t$ is 4.01 with 14 degrees of freedom and with a significance of 0.00 , which is smaller than 0.05 ; therefore, as a conclusion it could be held that there is a significant difference between the high-achieving and low-achieving groups with respect to the number of errors in the Stroop test. The low-achieving group had significantly more errors compared to the high-achieving group. Furthermore, the mean for the errors in the low-achieving group $(\mathrm{M}=1.27)$ was compared to that of the high-achieving group, which was zero, which shows a significant difference and indicates a better performance for the high-achieving group.

\section{Discussion}

Learning mathematics effectively and through a little effort is among the basic skills which are practiced in the first years at school. Educational problems among students in this period are usually discussed as 'educational underachievement'. Thus, considering students' educational level (in our study, math level) should be a research priority. One cause presented for the problems in mathematics is deficiency in non-executive functions (Geary, 1993). This study focused on working memory and inhibition with respect to math performance. The present study examined high-achieving and low-achieving students in mathematics in terms of working memory through forward and backward memory span tests.

There was a significant difference between these students, with low-achieving students in mathematics achieving lower scores on working memory than high-achieving students, a result consistent with Monette, Bigras and Guay (2011), Swanson, Jerman, and Zheng (2008), and Swanson and Sachse (2001). Importantly, the result was significant after controlling for intelligence and reading ability. Nonetheless, other studies have reported no significant difference in working memory between students who had problems in math and made good educational progress and those who did not (e.g., Geary et al., 2000; Butterworth, 2005; Temple \& Sherwood, 2002). Bull and Scerif (2001) used the Math Test for measuring the abilities of a group of children and reported a significant correlation between executive functions and math performance including inhibition, movement, and working memory; however, this correlation was not significant after controlling reading comprehension and intelligence. It could be said that mathematical abilities of a child are less automatized than an adult and requires a cognitive storage system to store temporary results, which can be helpful for the working memory and help students save the information they receive. It should be added that as a function of age, the portion that the working memory has for mathematical abilities is different for children. In addition, it could be held that development in mathematical abilities has a more significant role in younger children (Rasmussen \& Bisanz, 2005, cited in Andersson \& Lyxell, 2007), and younger students are in more need for this action. In a similar vein, some studies have shown that for younger children, more application of working memory resources is required when dealing with first experiences and skills. As children grow up, the learning has already taken place and restoration is extensively used, thus, obviating the need to use higher capacity of the working memory (Geary, Hamson, \& Hoard, 2000). Since our population included elementary school students, the capacity of the working memory involved was more effective in their math performance. Besides, low-achieving students showed significantly weaker performance in response to inhibition than the high-achieving students, which is consistent with a number of studies in the literature (e.g., Blair \& Razza, 2007; Lan et al., 2011). Swanson and Sachse (2001) maintain that inhibition can predict math progress and it affects the math performance of students. The relationship between inhibition and mathematical subscales, such as mono-digit and multi-digit addition and subtraction, can be so strong that even after the IQ and reading comprehension are controlled, this relationship remains significant in particular tests such as Stroop Test 
(Bull \& Scerif, 2001). Yet some studies (e.g., Visu-Petra, Benga, \& Miclea, 2011; Monette, Bigras, \& Guay C, 2011; Bull, Espy, \& Wiebe, 2008; Censabella \& Noël, 2008) found no significant relationship between inhibition and mathematical problems and showed that poor performance in mathematics is not caused by inhibition deficiency. Regarding the relationship between inhibition and working memory, people with better working memory can concentrate on inhibition tasks better than people with lower working memory capacity (Angel, 2002, cited in Lan et al., 2011). Similarly, this study demonstrated that students with a higher working memory capacity were more successful in response to inhibition and made no errors in the Stroop test, and thus showed better math performance. As regards the findings of this study, the contradictory findings between this study and other investigations can be explained by the differences in the methods applied including sample size, procedures, scoring, different control variables, and different instruments. As already pointed out, 10 in order to carry out mathematical tasks, students need a number of skills such executive functions. High-achieving students have automatically acquired and accordingly apply these skills, while low- achieving students face deficiency in this respect, which consequently leads to poorer math performance.

Teachers and parents can facilitate math learning for students. In addition, they should be aware that math learning is not accomplished merely by extensive practice and abundance of assignments. They should be aware of the individual differences e.g., executive functions and other effective factors as indicated in this study and adopt appropriate methods accordingly regarding the conditions of each student individually. Moreover, teachers can conduct more effective learning in the students during the teaching by attracting student's attention, speaking intelligibly and calmly, presenting complex instructions in smaller units/phases, and putting sufficient time for each phase of learning. Thus, with respect to the effects produced by the executive functions in enhancing students' performance in math, it could be concluded that, as the essential skills for learning math, these functions can be considered as an appropriate approach to dealing with problems hindering math performance. The present study used the standardized overall score of the Key-Math test; however, it seems that if the different math subtests which are not generally standardized were performed and the relationship between the scores for these subtests and executive functions were examined, the study could prove more effective in pinpointing the fundamental problems in math performance. This is the case because correcting mathematical problems requires an analysis of the problems encountered by each individual student, as in the Key-Math subtest. On the other hand, each student should be individually enabled to overcome these problems. This study used one instrument to measure each executive function; however, it seems that applying more instruments for determining the deficiencies in each of the functions is imperative and can yield more certain findings.

\section{References}

Alloway, T. P. (2006). How does working memory work in the classroom? Educational Research and Reviews, 1 , 134-139.

Andersson, U., \& Lyxell, B. (2007). Working memory deficit in children with mathematical dificulties: A general or specific deficit? Journal of Experimental Child Psychology, 96, 197-228. https://doi.org/10.1016/j.jecp.2006.10.001

Archibald, S. J., \& Kerns, K. A. (1999). Identification and description of new tests of executive functioning in children. Child Neuropsychology, 5, 115-129. https://doi.org/10.1076/chin.5.2.115.3167

Arndt, D., Sahr, K., Opferman, M., Leutner, D., \& Fritz, A. (2013). Core knowledge and working memory as prerequisites of early school mathematics. South African Journal of Childhood Education, 3(1), 1-20. https://doi.org/10.4102/sajce.v3i1.29

Baddeley, A. D., \& Hitch, G. J. (1974). Working memory. In G. H. Bower (Ed.), The psychology of learning and motivation: Advances in research and theory (Vol. VIII, pp. 47-90). New York: Academic Press. https://doi.org/10.1016/S0079-7421(08)60452-1

Baron, I. S. (2004). Neuropsychological evaluation of the child. New York: Oxford University press.

Blair, C., \& Razza, R. (2007). Relating effortful control, executive function, and false belief understanding to emerging math and literacy ability in kindergarten. Child Development, 78, 647-663. https://doi.org/10.1111/j.1467-8624.2007.01019.x

Blair, C., Zelazo, D., \& Greenberg, M. (2005). The measurement of Executive Functions in Early childhood. $J$. Deuelopmental muropsychology, 28(2), 561-571. https://doi.org/10.1207/s15326942dn2802_1

Boone, K. B., Miller, B. L., Lesser, I. M., Hill, E., \& D’Elia, L. (1990). Performance on frontal lobe tests in healthy, older individuals. Developmental Neuropsychology, 6(3), 215-223. https://doi.org/10.1080/87565649009540462 
Bull, R., Espy, K. A., \& Wiebe, S. A. (2008). Short-term memory, working memory, and executive functioning in preschoolers: Longitudinal predictors of mathematical achievement at age 7 years. Developmental Neuropsychology, 33, 205-228. https://doi.org/10.1080/87565640801982312

Bull, R., \& Scerif, G. (2001). Executive functioning as a predictor of children's mathematics ability: Inhibition, switching and working memory. Developmental Neuropsychology, 19(3), 273-293. https://doi.org/10.1207/S15326942DN1903_3

Butterworth, B. (2005). The development of arithmetical abilities. Journal of Child Psychology and Psychiatry, 46(1), 3-18. https://doi.org/10.1111/j.1469-7610.2004.00374.x

Cain, K., Oakhill, J., \& Bryant, P. (2004). Children's reading comprehension ability: Concurrent prediction by working memory, verbal ability, and component skills. Journal of Educational Psychology, 96(1), 31-42. https://doi.org/10.1037/0022-0663.96.1.31

Censabella, S., \& Noël, M. P. (2008). The inhibition capacities of children with mathematical disabilities. Child Neuropsychology, 14, 1-20. https://doi.org/10.1080/09297040601052318

Connolly, A. J. (1988). Keymath; A Diagnostic Inventory of Essential Mathematics. U. S. A: Guidance Service. Inc

Cowan, N. (2014). Working memory underpins cognitive development, learning and education. Educational Psychology Review, 26(2), 197-223. https://doi.org/10.1007/s10648-013-9246-y

Geary, D. C. (1993). Mathematical disabilities: Cognitive, neuropsychological and genetic components. Psychological Bulletin, 114, 345-362. https://doi.org/10.1037/0033-2909.114.2.345

Geary, D. C., Hamson, C. O., \& Hoard, M. K. (2000). Numerical and arithmetical cognition: A longitudinal study of process and concept deficits in children with learning disability. Journal of Experimental Child Psychology, 77, 236-263. https://doi.org/10.1006/jecp.2000.2561

Gersten, R., Jordan, N., \& Flojo, J. R. (2005). Early identification and interventions for students with mathematics Difficulties. Journal of Learning Disabilities, 38, 293-304. https://doi.org/10.1177/00222194050380040301

Gioia, G. A., \& Isquith, P. K. (2004). Ecological assessment of executive function in traumatic brain injury. Developmental Neuropsychology, 23, 135-158. https://doi.org/10.1207/s15326942dn2501\&2_8

Karami, N. R., \& Moradi, A. (2005). Reading and Dyslexia Test. Tehran: Teacher Training Department (SID).

Lan, X., legare, C. H., Cameron, P. C., Li, S., \& Morrison, F. J. (2011). Investigating the links between the subcomponents of executive function and academic achievement: A cross-cultural analysis of Chinese and American preschoolers. Journal of Experimental Child Psychology, 108, 677-692. https://doi.org/10.1016/j.jecp.2010.11.001

Lezak, M. D., Howieson, D. B., Loring, D. W., \& Hannay, H. J. (2004). Neuropsychological Assessment (4th ed.). New York: Oxford University Press.

Lowrie, T., \& Whitland, J. (2000). Problem Solving as a tool for learning. Planning and assessment in primary school in T. Nakahara.

MacLeod, C., \& Gorfein, D. (2007). Inhibition in cognition. Washington, DC: American Psychological Association. https://doi.org/10.1037/11587-000

McCloskey, G., Perkins, L. A., \& Van Divner, B. (2008). Assessment and intervention for executive function difficulties. New York: Routledge Press. https://doi.org/10.4324/9780203893753

Miyake, A., Friedman, N., Emerson, M., Witzki, A., \& Howerter, A. \& Wager, T. D. (2000). The unity and diversity of executive functions and their contributions to complex "frontal lobe" tasks: A latent variable analysis. Cognitive Psychology, 41(1), 49-100. https://doi.org/10.1006/cogp.1999.0734

Molfese. V. J., Molfese. P. J., Molfese. D. L., Rudasill, K. M., Armstrong, N., \& Starkey, G. (2010). Executive function skills of 6-8-year olds: Brain and behavioral evidence and implications for school achievement. Contemporary Educational Psychology, 35(2), 116-125. https://doi.org/10.1016/j.cedpsych.2010.03.004

Monette, S., Bigras, M., \& Guay, M.-C. (2011). The role of the executive functions in school achievement at the end of Grade 1. Journal of Experimental Child Psychology, 109, 158-173. https://doi.org/10.1016/j.jecp.2011.01.008

Montague, M. (2007). Self-regulation and mathematics instruction. Learning Disabilities Research \& Practice, 
22(1), 75-83. https://doi.org/10.1111/j.1540-5826.2007.00232.x

Montague, M., \& Applegate, B. (1993). Mathematical problem-solving characteristics of middle school students with learning disabilities. Journal of Special Education, 27(2), 175-201. https://doi.org/10.1177/002246699302700203

Mulhearn, S., \& George, K. (1999). Abdominal muscle endurance and its association with posture and low back pain. An initial investigation in male and female elite gymnastics. Physiotherapy, 85(4), 210-216. https://doi.org/10.1016/S0031-9406(05)65666-0

Nigg, J. T., Blaskey, L. G., Huang-Pollock, C. L., \& Rappley, M. D. (2002). Neuropsychological executive functions and DSM-IV ADHD subtypes. Journal of the American Academy of Child and Adolescent Psychiatry, 41, 59-66. https://doi.org/10.1097/00004583-200201000-00012

Papadakis, S., Michail, K., \& Nicholas, Z. (2017). Improving mathematics teaching in kindergarten with realistic mathematical education. Early Childhood Education Journal, 45(3), 369-378. https://doi.org/10.1007/s10643-015-0768-4

Passolunghi, M. C., \& Siegel, L. S. (2004). Working memory and access to numerical information in children whit disability in mathematics. Journal of Experimental Child Psychology, 88, 348-367. https://doi.org/10.1016/j.jecp.2004.04.002

Pennington, B. F., \& Ozonoff, S. (1996). Executive functions and developmental psychopathology. Journal of Child Psychology and Psychiatry, 37, 51-87. https://doi.org/10.1111/j.1469-7610.1996.tb01380.x

Repovs, G., \& Baddeley, A. D. (2006). The multi-component model of working memory: exploration in experimental cognitive psychology. Journal of Experimental Cognitive Psychology, 139, 5-21. https://doi.org/10.1016/j.neuroscience.2005.12.061

Shahim, S. (1994). Wechsler Intelligence Scale for Children-Revised. Shiraz: Shiraz University Press.

Spreen, O., \& Strauss, E. (1998). A compendium of neuropsychological tests: Adminsitration, norms, and commentary (2nd ed.). New York: Oxford University Press.

Stacey, K. (2005). The place of problem solving in contemporary mathematics curriculum documents. Journal of Mathematical Behavior, 24(3), 341-350. https://doi.org/10.1016/j.jmathb.2005.09.004

StClair-Thompson, H. L., \& Gathercole, S. E. (2006). Executive functions and achievements in school: Shifting, updating, inhibition, and working memory. The Quarterly Journal of Experimental Psychology, 59, 745-759. https://doi.org/10.1080/17470210500162854

Stevenson, C. E., Bergwerff, C. E., Heisera, W. J., \& Resinga, W. C. M. (2014). Working memory and dynamic measures of analogical reasoning as predictors of children's math and reading achievement. Infant and Child Development, 23(1), 51-66. https://doi.org/10.1002/icd.1833

Stroop, J. R. (1935). Studies of interference in serial verbal reactions. Journal of Experimental Psychology, 18, 643-662. https://doi.org/10.1037/h0054651

Swanson, H. L., \& Connor, O. R. (2009). The role of working memory and fluency practice on the reading comprehension of students who are dysfluent readers. Journal of Learning Disabilities, 42(6), 548-575. https://doi.org/10.1177/0022219409338742

Swanson, H. L., Jerman, O., \& Zheng, X. (2008). Growth in working memory and mathematical problem solving in children at risk and not at risk for serious math difficulties. Journal of Educational Psychology, 100, 343-379. https://doi.org/10.1037/0022-0663.100.2.343

Swanson. H. L., \& Sachse, L. C. (2001). Mathematical problem solving and working memory in children with learning disabilitie: Both executive and phonological processes are important. J Exp Child Psychol, 79, 294-321. https://doi.org/10.1006/jecp.2000.2587

Temple, C. M., \& Sherwood, S. (2002). Representation and retrieval of arithmetical facts: Developmental difficulties. Quarterly Review of Experimental Psychology, 55A, 733-752. https://doi.org/10.1080/02724980143000550

Valera, E. M., \& Seidman, L. J. (2006). Neurobiology of attention-deficit/hyperactivity disorder in preschoolers. Infants and Young Children, 19(2), 94-108. https://doi.org/10.1097/00001163-200604000-00003

Visu-Petra, L., Cheiea. L., Benga, O., \& Miclea, M. (2011). Cognitive control goes to school: The impact of executive functions on academic performance. Procedia Social and Behavioral Sciences, 11, 240-244. 
https://doi.org/10.1016/j.sbspro.2011.01.069

Welsh, M. C., \& Pennington, B. Y. (1988). Assessing frontal lobe functioning in children View from developmental psychology. Developmental Neuropsychology, 4, 199-230 https://doi.org/10.1080/87565648809540405

Wolfe, M. E. (2004). Executive function progress: Inhibition, working memory, planning and attention in children and youth with attention deficit hyperactivity disorder. $\mathrm{PhD}$ dissertation, Texas, A\&M University.

Zelazo, P. D., Muller, U., Frye, D., Marcovitch, S., Argitis, G., Bosevski, Chiang J. K., Hongwanishkul, D., Schuster, B. V., \& Sutherland, D. (2003). The development of executive function in early childhood. Monographs of the Society for Research in Child Development, 68(3), 138-151. https://doi.org/10.1111/j.1540-5834.2003.06803001.x

Zheng, X., Swanson, H. L., \& Marcoulides, G. A. (2011). Working memory components as predictors of children's mathematical word problem solving. Journal of Experimental Child Psychology, 110, 481-498. https://doi.org/10.1016/j.jecp.2011.06.001

\section{Copyrights}

Copyright for this article is retained by the author, with first publication rights granted to the journal.

This is an open-access article distributed under the terms and conditions of the Creative Commons Attribution license (http://creativecommons.org/licenses/by/4.0/). 